\title{
3 The Vagciriku-Lishora Massacre of 1894 Revisited
}

\author{
Shampapi Shiremo
}

\section{Introduction}

One day in March or April 1894, ${ }^{1}$ the Vagciriku community of the Kavango Region in Namibia and Cuando-Cubango Province in Angola lost almost all its able-bodied men. This happened after a force of armed BaTawana men on horseback, commanded by Kgosi $^{2}$ Sekgoma, which had travelled from Botswana, shot in cold-blood all the ablebodied Vagciriku men at a place called Shantjefu. ${ }^{3}$ Hompa Nyangana of the Vagciriku, his son, Mbambo, women and children were captured and taken into captivity in Ngamiland. The BaTawana army also confiscated all the Vagciriku cattle, guns and horses as booty.

Compared with colonial massacres in Namibian historiography such as the Hornkranz Massacre of 1893, the Old Location Massacre of 1959 or the Cassinga Massacre of 1978, the Lishora Massacre of 1894 is relatively unknown. The small body of literature about the Lishora Massacre of 1894 is generally one sided and situated outside the 'colonial narrative'. In Vagciriku oral history, Hompa Nyangana's despotism is usually blamed for the Lishora Massacre of 1894 as it is described as being a response to the conflict between Hompa Nyangana and the section of the Vashambyu led by Hompaghona (Prince) Kanyetu. Hompa Nyangana is sometimes remembered as an authoritarian leader who used violence to settle scores with his rivals. The view that Hompa Nyangana played a direct role in the Lishora massacre has never been critically questioned, because the existing secondary literature and oral narratives ignored the primary and archival sources kept in Botswana's National Archives. It appears evident that in the past, Namibian researchers on the Vagciriku-Lishora Massacre of 1894 remained totally unaware of the

1 In August 2008, I found a document in the Botswana National Archives and Record Services which showed that the Vagciriku-Lishora Massacre took place in March or April 1894 (I will refer to this document in detail later in this chapter). Previously I had believed that the massacre took place in 1893, thus my BA mini-thesis was entitled 'The Lishora Massacre of 1893 and its effects on the Vagciriku Community'.

2 Kgosi is the title given to the hereditary leader of the BaTawana community. The title Hompa is used by the traditional leader of the Kwangali, Mbunza, Shambyu and Gciriku communities in the Kavango Regions of Namibia today, whilst the term Fumu is used by the Mbukushu leader.

3 Shantjefu is a village found in the Cuando-Cubango Province of Angola near the Kwito River in the Gciriku area. It was at this village where the Vagciriku men were assembled by Kgosi Sekgoma and later on massacred in cold blood. After the massacre, Shantjefu became known as Lishora. It appears that in the old Rumanyo language, 'kushora' also meant to shoot. In contemporary Rukavango a powerful shot in soccer/football is called 'lishora', so Lishora could mean 'a place of shootings' or 'a place of death.' 


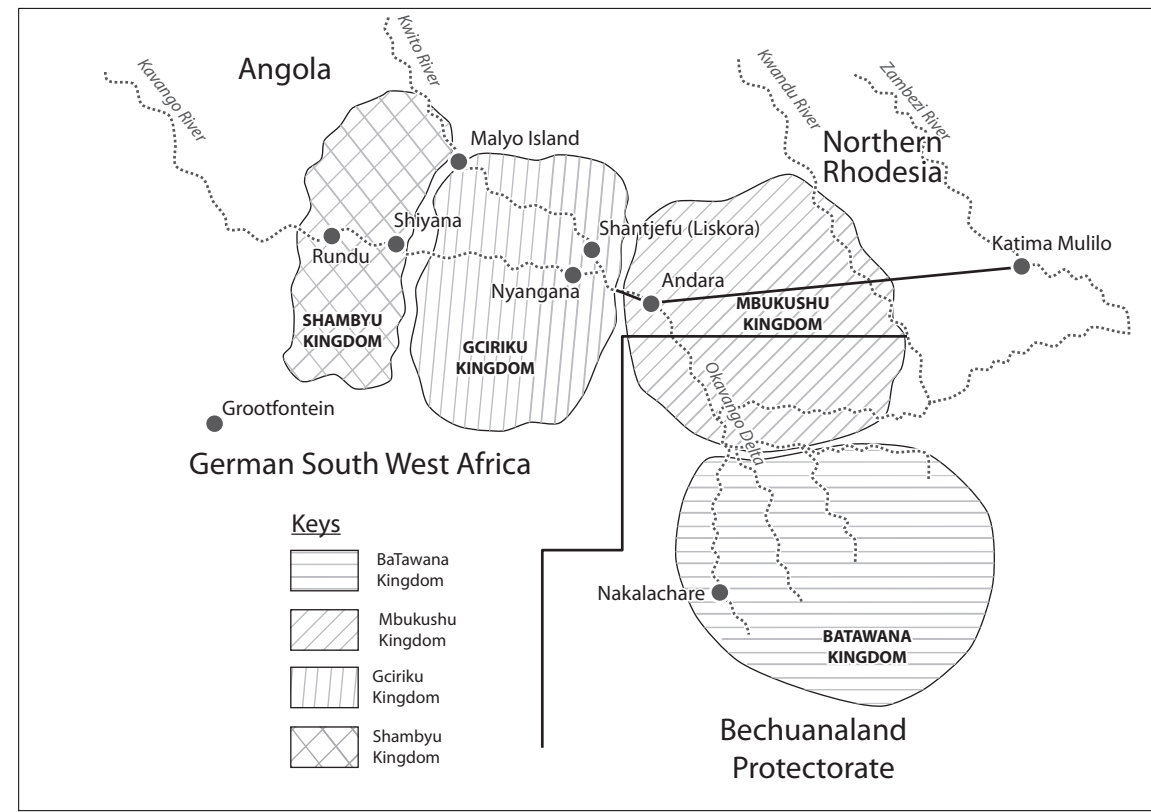

Figure 3.1 Map of the Gciriku, Batawana, Mbukushu and Shambyu Kingdoms in the 1890s

availability of archival sources on the topic in Botswana's National Archives. ${ }^{4}$ Thus, it is not surprising that though John Mutorwa was exposed to the local oral written sources on the causes of the Lishora Massacre, he concluded his work by calling for further research into the matter as, he argued, the causes of the Lishora tragedy are not altogether known (Mutorwa, 1996, p. 11). However the main focus of Mutorwa's research was not to investigate the causes of the Vagciriku-Lishora Massacre, but to focus on another aspect of Vagciriku history.

This chapter focuses on important, newly discovered, contemporary documents produced by BaTawana and the European officials who were tasked to investigate the causes of the Vagciriku-Lishora Massacre of 1894 and highlights the differences between these contemporary written accounts and oral tradition in the region. ${ }^{5}$ Whilst the oral tradition focuses on the internal politics of the kingdom and the tensions in its relationships with neighbouring states, the archival evidence locates the conflict within the context of contemporary imperial rivalries.

Written accounts of the Vagciriku-Lishora Massacre are found in both primary and secondary sources. The primary sources appear in the form of correspondence and

$4 \quad$ This author was alerted to the existence of this material in around June 2008 by Dr Jeremy Silvester and Werner Hillebrecht who compiled a list of historical files that are relevant to Namibian history held by the Botswana National Archives.

5 BNARS (Botswana National Archives and Record Services). HC 144. Correspondence on Ngamiland Affairs and the Ghanzi District and Lake Ngami Police detachment. Boer Trekkers, Isaac Johan Bosman acting on behalf of the BSACo, and papers relating to the murder of a German subject, Phillip Wiesels and a British subject, Robert Arthur Faraday, by Nyangana and the capture of Nyangana by Sekgoma's men (1894-1898). 
statements from the Bechuanaland British Protectorate's colonial officials during the period 1893 to 1896 . These officials had written down contemporary accounts by the BaTawana. Kgosi Sekgoma and other prominent BaTawana appear to have given statements to the Bechuanaland British Protectorate Administration. Secondary sources that refer directly to the Lishora Massacre are found in a book and an article that were published nine and ten years after the incident. The book is by Major Hill Gibbons (1904) entitled Africa: From the South to North through Marotseland, and the article is entitled 'Die Mambukuschu' by Professor Siegfried Passarge (1905). Whilst these two publications date from 1904 and 1905, the two authors state that they recorded their accounts between 1898 and 1900, only a few years after the massacre, when memories of the event were still fresh. There are a few other publications that make reference to the Lishora Massacre, with an article called 'Die Diriku' by August Bierfert (1913) and another entitled Founding a Protectorate: History of Bechuanaland, 1885-1895 by A. Sillery (1965), being the most significant.

\section{Friction with White Traders}

Two white traders, Phillip Wiesel (or Weise) and Robert Arthur Faraday, were killed in 1892 - at a historical moment when colonial powers were attempting to define the boundaries of their territorial claims in the wake of the Berlin Conference of 1884. The kingdoms in this part of Africa were on the periphery of the expanding territorial claims of three European powers - Germany, Britain and Portugal. One might argue that Hompa Nyangana's orders to kill the two European traders were an effort to assert his local autonomy and a direct challenge to the imposition of colonial rule and foreign control over long-distance trade. It appears that the shooting of the two traders was a decision taken at the Vagciriku King's council after extensive debate. At this meeting, some relatives and Vagciriku council members were reported to have advised Hompa Nyangana against this course of action with one arguing: 'that is not good, the white men will turn on us and the Lake natives.' Hompa Nyangana replied to this, 'I don't know much about the white men, but I am sure the Lake natives [i.e. Sekgoma's community] will be satisfied'. 6

Before 1892, the Vagciriku were involved in two other incidents in which they killed European traders. The first incident took place shortly before 1878 and involved Portuguese traders, and the second incident took place on the 27 July 1878 and involved the killing of an American trader, Charles Thomas. The second incident provoked a retaliatory attack from a force led by European traders based in the region. Though putting up a spirited resistance, the Vagciriku were defeated as about 22 Vagciriku men were reportedly killed and many more wounded (McKiernan, 1954, p. 176). At that time Hompa Nyangana fled his kingdom to Ukwangali where he was given asylum for a short period before he returned to his kingdom. Many of the Vagciriku homesteads, including Hompa Nyangana's own palace, were burned in this attack (McKiernan, 1954, p. 168).

$\overline{6}$ BNARS: HC 144 . A letter dated 10 December 1895 by Lieutenant Barre Phipps to the Resident Commissioner. 